\title{
MOVILIZACIONES Y DECLARACIÓN CONTRA LA PROPUESTA DE DIRECTIVA DE PATENTES DE PROGRAMACIÓN
}

\section{MOBILIZATION AND DECLARATION AGAINST THE PROPOSED SOFTWARE PATENT DIRECTIVE}

ProInnova: grupo de interés de Hispalinux y de ATI (Asociación de Técnicos en Informática), a favor de la libertad de innovación. Actualmente mantiene (entre otras) una campaña a favor de una Europa libre de patentes de programación (también llamadas patentes de software). Hispalinux es la mayor asociación de promoción del software libre en España, con más de 6.000 miembros.

jesus.gonzalez@hispalinux.es

\section{RESUMEN}

Desde el 27 de agosto se están organizando, a nivel europeo, una serie de actividades y movilizaciones contra la propuesta de directiva de patentes de programación. Con este motivo varias asociaciones han difundido un comunicado que apoya las movilizaciones en contra de los planes de la Unión Europea de implantar patentes de software.

\section{PALABRAS CLAVE}

Directiva - Patentes - Programación - Unión Europea 


\section{ABSTRACT}

From the August 27 are being organized at European level, a series of activities and demonstrations against the proposed directive on software patents. On this occasion several associations have released a statement supporting the protests against European Union plans to introduce software patents.

\section{KEY WORDS}

Directive - Patents - Programming - European Union

\section{TEXTO:}

Desde el 27 de agosto se están organizando, a nivel europeo, una serie de actividades y movilizaciones contra la propuesta de directiva de patentes de programación. Con este motivo varias asociaciones han difundido el siguiente comunicado:

Madrid, Barcelona, 21 de agosto de 2003

El comunicado conjunto de las organizaciones abajo firmantes apoya las movilizaciones en contra de los planes de la UE de implantar patentes de software y asumen la siguiente declaración:

Consideramos que la legalización de las patentes de programación en Europa causaría grandes perjuicios a la sociedad de la información europea en general, y a la capacidad de innovación y desarrollo de los profesionales y las empresas del sector 
en particular. Por otro lado, creemos que esta legalización no fomenta de ninguna manera la investigación y el desarrollo en el campo de los programas de ordenador, ni la producción de programas que satisfagan mejor (cualitativa y cuantitativamente) las necesidades de los ciudadanos y las empresas europeas.

Por ello solicitamos a las instituciones con competencia en este asunto que tomen las medidas necesarias para asegurarse de que la legislación sobre patentabilidad no afecta a los programas de ordenador, que quedarán por lo tanto sujetos de forma exclusiva a la legislación sobre derechos de autor (copyright), que hasta el momento se ha mostrado como la más adecuada para ellos. Así mismo, instamos a estas instituciones a clarificar la situación legal en este sentido en los aspectos y términos que sea necesario.

Los programas de ordenador están sujetos en todo el mundo a la legislación sobre derechos de autor, de forma similar a como están sujetas, por ejemplo, las obras literarias. Esta legislación permite que el autor (o quien detente los derechos) mantenga ciertos derechos, como prohibir la redistribución del programa o la realización de trabajos derivados de él. Sin embargo, no propone ninguna restricción para el desarrollo de obras independientes e innovadoras por cualquier otra parte.

En algunos estados los programas están sujetos también a la legislación sobre patentes, que permiten obtener monopolios de comercialización de tecnologías durante periodos de 20 años, y que impiden la comercialización de las tecnologías patentadas por terceras partes, incluso aunque hayan sido descubiertas de forma totalmente independiente. Consideramos que esta forma de protección no es adecuada para los programas de ordenador, que su impacto económico y sobre la innovación es negativo, y que el sector informático puede desarrollarse 
perfectamente sin ella, como ha sucedido hasta muy recientemente incluso en los países donde se ha introducido últimamente».

Esta iniciativa de la UE tendría, entre otros, los siguientes efectos negativos:

* Reduciría la innovación y reforzaría los monopolios en un recurso tan básico como el software, perjudicando así tanto las posibilidades de elección de los consumidores, como la relación calidad-precio de los productos y servicios en este sector y privando a los ciudadanos de una sociedad de la información sana.

* Perjudicaría el comercio electrónico al permitir la extorsión legal por parte de poseedores de patentes de software.

* Comprometería las libertades de creación, publicación y comercialización de los resultados del trabajo propio (el poseedor de una patente podría impedir la publicación o comercialización de un programa original por su propio autor).

* Causaría incertidumbre legal a los poseedores de derechos de autor por causa de la inflación de patentes (no sabrían si están infringiendo una patente de algún tercero hasta que les llegue la amenaza o la citación judicial correspondiente).

* Pondría en peligro a los profesionales y PYMEs que no tienen los recursos para acumular patentes o ir a juicio, y representan la mayoría de la ocupación y la innovación en tecnologías de la información en la Unión Europea.

* Introducirían una contradicción legal fundamental al usar patentes para monopolizar información (los programas son simplemente información) en lugar de su propósito original de difundir información sobre invenciones. 
Por estos motivos

* La Asociación de Usuarios Linux de España, Hispalinux

* La Asociación de Internautas, AI

* ProInnova

* Softcatalá

* Federación de Servicios Financieros Comfia-CCOO

Apoyan las movilizaciones que dentro y fuera de la Red han sido convocadas.

Hacen un llamamiento a los eurodiputados españoles para que tomen las medidas necesarias para asegurarse de que la legislación sobre patentabilidad no afecta a los programas de ordenador y

Animan a los webmasters para que desde el día 27 de agosto se exhiban en sus sitios web adhesiones de protesta.

\section{Webgrafía}

Información sobre la propuesta de directiva

http:/ / proinnova.hispalinux.es/infopaquetes/directiva-patsw /

Información sobre los actos 27 de agosto

http:// proinnova.hispalinux.es/campanyas/movi-27ago/index.html

Asociación de Internautas

http://www.internautas.org 
Softcatalá

http://www.softcatala.org

\section{Comfia-CCOO}

http://www.comfia.net

Las patentes de software: un problema para Europa (informe del grupo ProInnova) http:// proinnova.hispalinux.es/infopaquetes/carta-directiva/index.html 